\title{
ОЦЕНКА ИНВЕСТИЦИОННОЙ ПРИВЛЕКАТЕЛЬНОСТИ ЦИФРОВЫХ ТЕХНОЛОГИЙ В ЖЕЛЕЗНОДОРОЖНОЙ ОТРАСЛИ
}

\author{
(C) 2021 Гулый Илья Михайлович \\ кандидат экономических наук, доцент \\ Петербургский государственный университет путей сообщения Императора Александра I, \\ Россия, Санкт-Петербург \\ E-mail: ilya.guliy@mail.ru
}

Показаны статистические тренды инвестирования в цифровые технологии по видам транспорта в России. Отмечена опережающая динамика инвестиций в цифровые технологии в сравнении с общей макроэкономической динамикой. Систематизированы возможные методологические подходы к экономической оценке инвестиций в цифровые технологии. Верифицирована гипотеза об инвестиционной привлекательности, существенной экономической эффективности проектов цифровизации на основе анализа передового опыта внедрения проектов железнодорожными компаниями в мире.

Ключевые слова: инвестиции в циффровые технологии, инвестиционная привлекательность, цифровые инвестиции, цифровая модель, цифровизация железнодорожного транспорта.

Введение.

Цифровая революция предопределила первоочередное внимание руководства компаний всех отраслей к проектам внедрения передовых digital-технологий и сервисов. Инвестиции в цифровые технологии растут опережающими темпами в сравнении с объемами производства продукции и услуг, добавленной стоимостью. Так, национальным проектом России «Цифровая экономика» предопределен рост внутренних затрат на развитие цифровой экономики за счет всех источников по доле ВВП в 3 раза: с $1,7 \%$ в 2018 г. до 5,1\% к 2024 г. Вместе с тем, экономическая оценка инвестиций в проекты цифровизации, с научно-методологической точки зрения, рассматривается сегодня как полигон для исследований, формирования новых знаний, выработки рекомендаций, предложения подходов, поиска новизны.

Результаты исследований.

Тренды цифровых инвестиций в российском транспортном комплексе.

За последние годы инвестиции в цифровые технологии по российскому транспорту росли опережающими темпами в сравнении с общей макроэкономической динамикой добавленной стоимости. Так, прирост инвестиций в целом по транспорту с 2015 по 2020 гг. в действующих ценах составил $110 \%$, а прирост валовой добавленной стоимости за тот же период лишь $35 \%$. Наибольшие темпы прироста отметим по воз- душному, водному видам транспорта, складскому комплексу и вспомогательной обслуживающей транспортной деятельности (более, чем в 3 раза)-рисунок 1.

Подходы к экономической оценке инвестиций в цифровые технологии.

На наш взгляд, привлекательность инвестиций в цифру должна оцениваться комплексом методик. В частности, предлагается использовать:

- ретроспективный анализ соотношения затрат (инвестиций) и результатов (эффектов);

- сравнительный анализ на основе передового опыта внедрения технологий в мире - бенчмаркинг;

- сложное многофакторное математическое моделирование;

- балансовые методики, включая построение межотраслевых балансов, оценку мультипликативных эффектов цифровых инвестиций с учетом межотраслевых связей и пропорций [5];

- детализированное технико-экономическое обоснование конкретного проекта с получением экспертных заключений, опросом заинтересованных сторон - участников проектов цифровизации.

В наиболее общем виде экономический эффект цифровизации железнодорожных перевозок заключается в обеспечении оперативности и актуальной информации для быстрого принятия решений по управлению перевозками и ин- 


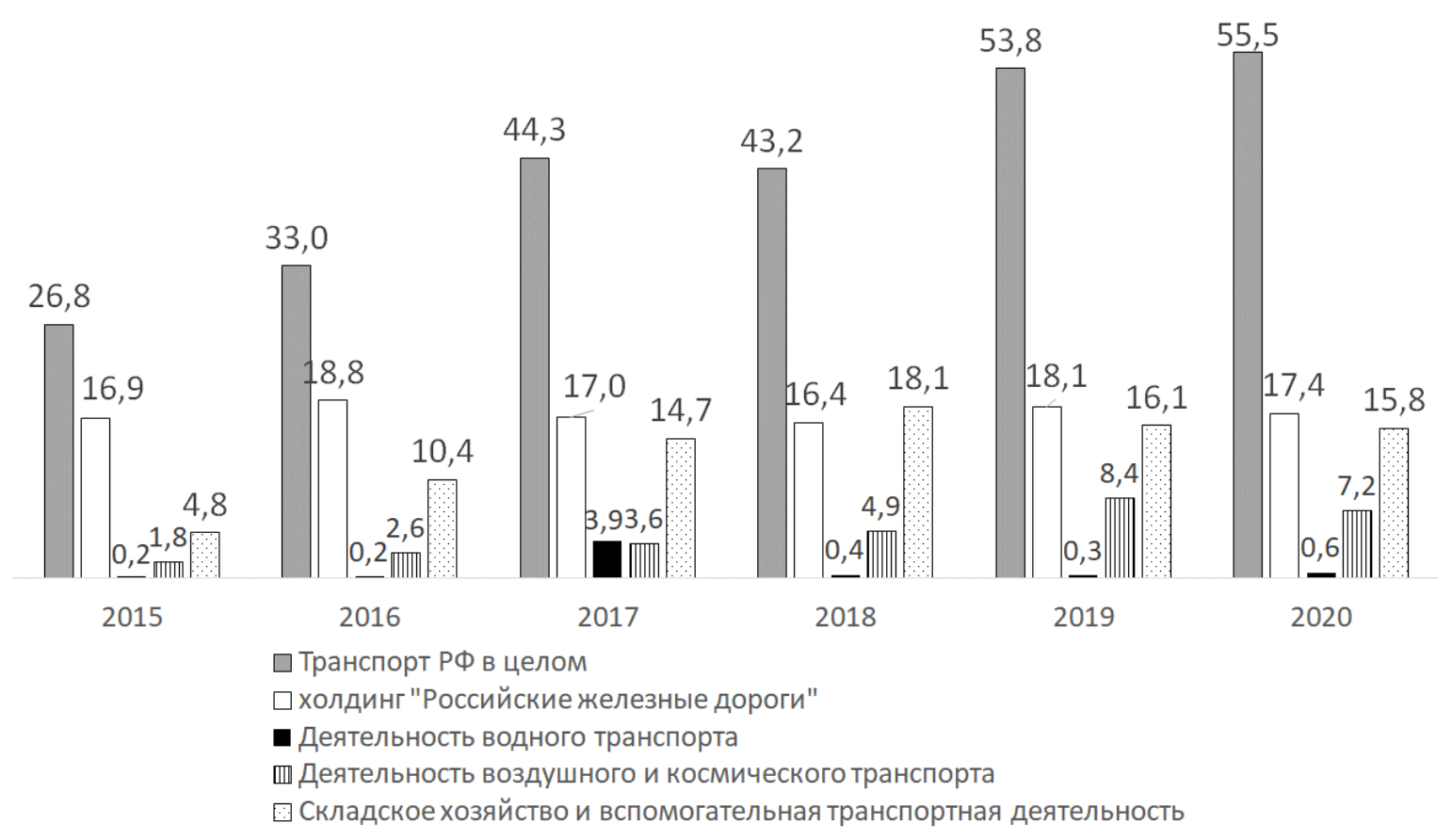

Puc. 1. Динамика инвестиций в цифровые технологии по российскому транспорту в целом, в том числе по основным видам транспорта с 2015 по 2020 гг., в действующих ценах соответствующего периода, млрд. рублей

Источник: построено автором на основе [2].

Данные за 2020 г. приведено оценкой в расчете на год по итогам информации Росстата за 9 месяцев 2020 г.

фраструктурой, что приводит к:

- сокращению себестоимости - операционных затрат;

- созданию ресурсосберегающих, экономичных систем;

- увеличению прибыли;

- росту физического объема железнодорожных перевозок;

- повышению уровня безопасности;

- развитию железнодорожной инфраструктуры при минимизации потерь, устранении последствий старения основных фондов, своевременном внедрении технологических инноваций.

Детализация возникновения экономического эффекта по различным видам цифровых технологий приведена в таблице 1.

Бенчмаркинг существующей практики внедрения цифровых технологий в железнодорожной отрасли в мире.

1. Технологии Интернета вещей (IоT). Итальянской железнодорожной компанией Trenitalia в 2017 году внедрен проект датчиков и интеллектуальных устройств на поезда для получения актуальных данных в режиме реального времени об их работе, возможности непрерывной удаленной диагностики подвижного состава в непрерывном. Инвестиции в проект в пе- ресчете в российские рубли составили порядка 3,5 млрд., при этом годовое сокращение затрат на техническое обслуживание оценивалось в 7 млрд. рублей (рублевый эквивалент евро), сокращение расходов ввиду отсутствия компенсаций за задержку рейсов порядка 0,7-1,2 млрд. рублей в год.

2. Внедрение интеллектуальных систем управления, робототехники. Такие проекты можно рассмотреть на примере городского подземного транспорта - метрополитена. Управление движением поездов без участия машиниста позволило компаниям в Великобритании, Канаде, Германии, Италии, Франции, Испании, Швейцарии, США с других странах сократить операционные расходы до 30\% в год. При этом объем инвестиций вырос в среднем примерно на $10 \%$ в сравнении с проектами строительства обычных линий метро.

3. Проекты непрерывной обработки и анализа больших массивов данных (Big Data). Ha опыте той же итальянской железнодорожной компании Trenitalia проект предиктивной аналитики состояния инфраструктуры и подвижного состава (оценка инвестиций 0,8 млрд. рублей) позволил добиться своевременного прогнозирования их поломки. За счет своевременной корректировки плана по ремонту техники за- 
Таблица 1. Основные направления эффектов цифровых технологий

\begin{tabular}{|c|c|}
\hline Название технологии & Эффекты \\
\hline Интернет вещей (IoT) & $\begin{array}{l}\text { Сокращение количества и длительности простоев } \\
\text { Рост энергоэффективности } \\
\text { Снижение расходов на ремонт } \\
\text { Уменьшение эксплуатационных расходов }\end{array}$ \\
\hline $\begin{array}{l}\text { Обработка и анализ больших дан- } \\
\text { ных (Big Data) }\end{array}$ & $\begin{array}{l}\text { Повышение эффективности бизнес-процессов } \\
\text { Предотвращение оттока клиентов, получение эффектов за счет быстро- } \\
\text { го реагирования на спрос } \\
\text { Достижение эффектов за счет гибкого и оптимального тарифообразо- } \\
\text { вания } \\
\text { Сокращение расхода материальных ресурсов } \\
\text { Повышение эффективности использование активов компании }\end{array}$ \\
\hline $\begin{array}{l}\text { Распределенные реестры данных } \\
\text { (blockchain) }\end{array}$ & $\begin{array}{l}\text { Предотвращение непредвиденных сбоев, потерь данных, несанкциони- } \\
\text { рованного вмешательства в системы } \\
\text { Реализация мультимодальных и безшовных технологий }\end{array}$ \\
\hline $\begin{array}{l}\text { Интеллектуальные системы, робо- } \\
\text { тотехника }\end{array}$ & $\begin{array}{l}\text { Сокращение затрат на топливо и энергию } \\
\text { Уменьшение времени и простоев при формировании грузового состава } \\
\text { Сокращение времени, снижение затрат труда при внедрении безлюд- } \\
\text { ных технологий формирования отчетности, принятия оперативных } \\
\text { решений, выполнении вспомогательных рутинных операций } \\
\text { Сокращение ошибок и влияния человеческого фактора, уменьшение } \\
\text { потерь в результате ошибок }\end{array}$ \\
\hline $\begin{array}{l}\text { Виртуальная и дополненная реаль- } \\
\text { ность (AR, VR) }\end{array}$ & $\begin{array}{l}\text { Сокращение расходов на обучение и подготовку персонала } \\
\text { Предотвращение потерь }\end{array}$ \\
\hline $\begin{array}{l}\text { Квантовые технологии вычисле- } \\
\text { ний и передачи данных }\end{array}$ & $\begin{array}{l}\text { Обеспечение высокого уровня информационной безопасности и защи- } \\
\text { ты данных } \\
\text { Рост скорости обработки данных, вычислений и принятий решений }\end{array}$ \\
\hline $\begin{array}{l}\text { Цифровое моделирование в желез- } \\
\text { нодорожном строительстве (BIM) }\end{array}$ & $\begin{array}{l}\text { Сокращение сроков строительства } \\
\text { Уменьшение инвестиций в проекты строительства инфраструктуры }\end{array}$ \\
\hline
\end{tabular}

Источник: авторская разработка, систематизация на основе [1, 2, 4].

траты на техническое обслуживание и ремонт сократились в диапазоне от 5 до $10 \%$.

4. Цифровое моделирование и ВIM-технологии. Внедрение виртуальных технологий предотвращения ошибок в железнодорожном строительстве на примере проекта строительства линии Crossrail в Великобритании (оценка инвестиций в 0,9 млрд. рублей по официальному валютному курсу) способствовало сокращению ошибок. Как следствие, снижение потерь и дополнительных инвестиций на 25\%. Такого эффекта удалось достичь, благодаря тому, что BIM-технологии позволили проектировать создание объектов инфраструктуры на основе постоянного анализа баз данных проектной документации [4].

В завершение исследования отметим, что дополнительным преимуществом цифровой модели железнодорожного бизнеса является способность видеть и управлять всей технологической системой целиком в неразрывной увязке всех элементов, а не как управление отдельными локализованными бизнес-блоками и процессами. Это даст возможность своевременно, быстро реализовывать запросы граждан и бизнеса на мобильность, скорость, качество, сервис. Железнодорожный транспорт будущего будет ориентирован на: глобальную и локальную мультимодальность, развитие грузового скоростного сообщения, широкое внедрение высокоскоростных пассажирских магистралей, быструю реакцию перевозчиков по внутренним процессам и внешнюю среду, достижение наивысшей степени надежности и безопасности. Все это невозможно без диджитализации бизнеса, где большая часть добавленной стоимости будет создаваться с преобладанием цифровых систем.

\section{Заключение}

Таким образом, можно заключить, что современная цифровая трансформация отличается высоким динамизмом инвестирования в соответствующие системы и технологии. Привлекательность инвестиций в развитие цифрового транспортного бизнеса подтверждается тем, что получение всесторонних выгод, экономических эффектов, оптимизация капиталовложений, ресурсов, затрат выступают как доказанный, всесторонне обоснованный экономический императив. 


\section{Библиографический список}

1. Scott J., Zhuravleva N.A., Durana P., Cug J. Public acceptance of autonomous vehicle technologies: attitudes, behaviors, and intentions of users // Contemporary Readings in Law and Social Justice. 2020. T. 12. No 1. P. 23-29.

2. ЕМИСС Государственная статистика: Официальные статистические показатели [Электронный ресурс]. URL: https://fedstat.ru (дата обращения: 29.09.21).

3. Казанская Л.Ф., Ризакулов Ш. Ш. Развитие информационных систем в управлении безопасностью движения национальной железнодорожной компании // Транспорт России: проблемы и перспективы - 2018. Материалы международной-научно-практической конференции. 2018. С. 55-59.

4. Транспорт. Технологии. Тренды: аналитический обзор. Москва: АО «ИК «РЖД-Инвест», 2020. 157 с.

5. Чеченова Л. М. Интеллектуализация железнодорожного транспорта как фактор развития транспортной отрасли // Вестник транспорта Поволжья. 2021. № 2 (86). С. 78-85. 